\title{
Interactive Session: Measuring the Impact of Connection to Community
}

\section{Dr. Rebecca A Bates, Minnesota State University, Mankato}

Dr. Rebecca A. Bates received the Ph.D. degree in Electrical Engineering from the University of Washington in 2004. She also received the M.T.S. degree from Harvard Divinity School in 1993. She is currently professor and chair of the Department of Integrated Engineering program at Minnesota State University at Mankato. She was a 2011-12 AAAS Science \& Technology Policy Fellow at the National Science Foundation.

\section{Dr. Julie P Martin, Clemson University \\ Dr. Denise Wilson, University of Washington}

Dr. Denise Wilson received the B.S. in Mechanical Engineering from Stanford University in 1988 and the M.S. and Ph.D. degrees in Electrical Engineering from the Georgia Institute of Technology in 1989 and 1995, respectively. She also earned her M.Ed. from the University of Washington in 2008 and has worked in Applied Materials. She is currently a faculty member with the Electrical Engineering Department at the University of Washington, Seattle, and she was previously with the University of Kentucky, Lexington, in a similar position from 1996 to 1999 . Her research interests are split between technical investment in biological and chemical-sensing microsystems and equivalent interest in engineering education, with particular emphasis on affective and metacognitive factors that influence student success in STEM fields.

\author{
Dr. Melani Plett, Seattle Pacific University \\ Dr. Tamara Floyd Smith, Tuskegee University
}




\title{
Interactive Session: Measuring the Impact of Connection to Community
}

\begin{abstract}
As awareness of the value of community engagement increases, programs associated with community engagement will be called upon more and more to evaluate program outcomes. This paper supports an interactive session that provides a wide variety of tools related to the use of quantitative, qualitative and mixed-methods approaches to evaluate how well and how much those involved in a community benefit from it. These tools are presented in the context of two different research studies where the evaluation of various community outcomes is a central goal of each study. Instruments used in each study and their validity for studying community are presented and provided in a manner readily transferrable to other researchers or practitioners who are studying the quality of community and community engagement. Challenges posed by human studies are also discussed. The goal of the session is to equip participants with the insight gained by these and related studies into the importance of community engagement and provide instruments for those involved in the development of communities to evaluate their own successes.
\end{abstract}

\section{Introduction}

The value of off-campus community engagement in engineering learning is becoming more apparent. The number of service learning, engineering without borders, international experiences, and other community engagement programs is increasing, while the impact of such programs ranges from local communities to international experiences. The proliferation of investment into these off-campus communities raises questions about how the value of these programs can be assessed in terms of student learning and related academic outcomes. This resource paper provides a toolbox of methods useful for assessing the impact and importance of off-campus community and social interaction for engineering students. Tools are drawn from two separate research studies. The first (Study 1) examines the impact of connections to community on academic outcomes and also the influence of various student activities on these connections to community. The second study (Study 2) examines the impact of social capital on choice of engineering as a major and persistence in the major and field. Such social capital can be developed through interactions with community at a wide range of levels, from the classroom or university and extending off-campus to neighborhood involvement and even into international experiences.

While these studies investigate both on and off campus communities, connections between students both inside and outside the classroom, the insights gained are often relevant to offcampus community engagement. Furthermore, the research instruments and methods used in these studies are, in many cases, directly transferrable to the evaluation of other off-campus communities at different lead by a wide range of researchers and practitioners. The models that these studies test are developed with generalizability in mind, so that connections within the models and corresponding hypotheses can be readily tested in other communities using the study instruments and similar recruiting techniques. Thus, we hope to use the efforts, results, and insights gained in both studies to benefit the communities made accessible to students through 
service learning, international study, and similar outreach experiences. These communities are the foundational core of both ASEE's Community Engagement Division and this special session.

\section{Interactive Session Plan}

This interactive session begins with a brief (20 minute) introduction to both studies by investigators in each study and a brief time for questions regarding the results and context of these studies. Following the introduction, 20 minutes are allocated to an overview of methods and a description of the research instruments and other tools used to achieve the results and study the models presented in the introduction. The remainder of the session (35 minutes) is reserved for interaction among participants and session organizers, focusing specifically on how the tools presented in this session can be applied to participant's activities, research, and experiences in service learning and other related outreach activities

Participants will leave this session with a toolbox of research instruments and a preliminary plan for how to apply those instruments to their own interests, studies, and activities. Discussion time will focus on formulating research questions and identifying research, assessment, or evaluation plans that suit the interests of participants in the context of how participation in particular communities can support improvements in a range of outcomes including social capital, belonging, engagement in the classroom, and others.

\section{Research Background \& Motivation}

A motivation for the community-based experiences highlighted in the engineering education practices like service learning is to improve academic engagement. Working to improve interest, i.e., engagement, as well as aptitude enables not only an increase in the number of students trained for the technical workforce but also a broadening of their capabilities beyond the purely technical. Engineers with this broader world view will be poised to lead valuable technical innovation in the 21 st century. ${ }^{1}$ The literature, gathered from higher education, K-12, and organizational psychology clearly supports the importance of community in influencing engagement and cognitive outcomes and performance. Belonging and other connections to community are known to be significant contributions to engagement in K-12 education. ${ }^{2-4} \mathrm{~A}$ greater sense of connection to community, ranging from the immediate (belonging) to the broad (affiliation) level can also enhance retention, thereby delivering greater numbers of engineers to the technical workforce. This theory is supported not only by the K-12 body of literature where belonging and membership in the school community are proven to influence drop out rates ${ }^{5}$ but also by higher education research that cites lack of community (isolation) as a primary reason for women to leave engineering fields ${ }^{6}$ and connection to faculty community as a strong contributor to Hispanic student persistence in academic endeavors. ${ }^{7}$ Improvements in retention resulting from increases in connection to community are fundamentally supported by the higher education model of social integration developed by Tinto, where student goals and commitments formed by pre-college attributes interact with their college experiences to indicate whether students are likely to complete an academic program. ${ }^{8-10}$ Community also begets community; students who have not experienced a strong sense of community (and belonging) in their undergraduate experience are far less likely, in the long term, to take a critical community leadership role in industry. Moving from academia to the work place, a sense of belonging can result in increased 
feelings of security, stronger self-concept, self-respect and coping abilities ${ }^{11}$ and is cited in organizational behavior texts as part of the definition of an organization (e.g., Liebler \& McConnell ${ }^{12}$ ). Thus, from the perspective of the 21 st century workforce, improved understanding of and ability to build community in the undergraduate STEM experience links to essential needs in the technological workforce.

Not only do we want to retain students throughout their STEM academic careers, we want their careers to be fulfilling and sustainable. Previous research in STEM education shows that student success can depend on integration of academic and social experiences (e.g., Treisman 1990 ${ }^{13}$; Treisman $1992^{14}$ ) which can be influenced by such learning support mechanisms as collaborative learning, faculty mentoring and creation of study cohorts. In a large study, the National Center for Statistics ${ }^{15}$ looked at the entry and persistence of women and minority students in science and engineering. They summarize that factors that cause students to opt out of STEM fields include family and economic background as well as academic and institutional factors. The results of these and related studies (including Lee \& Wilson ${ }^{16,17}$ ) make an indisputable case for the importance of social and emotional factors in influencing student success. Belonging (local connection to community) is especially important because it is a "...powerful, fundamental, and extremely pervasive" motivation of humans to fulfill needs for attachment through social bonds (Baumeister \& Leary ${ }^{18}$, p. 497).

However, reaping the benefits of connection to community can be especially challenging in introvert-dominated ${ }^{19}$ engineering and similar STEM fields because sense of community has been shown to be moderated by level of extraversion, ${ }^{11}$ thus making it substantially harder for introverts to develop these connections. Service learning programs and other projects that provide motivation for interactions while allowing work that may be individualized can support the development of a sense of community in introverted students.

Social capital can be defined as resources gained from relationships. In the context of engineering students' academic and career decisions, the second study finds that students' decisions to select engineering as a college major and to persist in undergraduate engineering studies are influenced by the available resources in their social networks, as well as the activation of those resources. Social networks and social capital characteristics are often viewed in terms of size and heterogeneity (with the idea that large, more heterogeneous networks typically result in more social capital). While this is often true, this study's preliminary results also reveal that sometimes only one person (a social capital "agent") or experience (i.e. resource) can also be influential in students' selection and persistence in engineering studies. Both of these points of view support the notion that connection to community can result in more social capital for engineering students, whether students are introverted or extroverted.

Methodologically, approaching questions of what? how? and why? can take different or multiple forms. To discover the breadth of what is happening, quantitative surveys can ask many subjects for open-ended answers to a question such as "what communities are you involved with?" or "what people are influential in your academic and career making decisions?" Surveys can establish a broad range of connections using Likert responses (i.e., 1-5 scale or strongly agree to disagree range). Factors such as strength of feelings related to a particular concept (asked with single or multiple questions) can be statistically evaluated to provide insight into student 
experiences on a broad scale. As we move towards developing conceptual models, incorporating qualitative methods either alone or in a mixed-methods approach allow researchers to gain rich, thick descriptions and directly from participants and in their own words. ${ }^{20-22}$ In designing a research study that answers what? how? and why? it is important to carefully consider both the purpose and advantages/disadvantages of each method selected for use (see study 2).

Triangulation of quantitative and qualitative methods enhances the rigor of the research. ${ }^{23-24}$

\section{Two Research Studies Highlighting the Benefits of Community Engagement}

Study 1: The goal of this study is to investigate connection to community, a central mediator in predicting and improving student academic engagement. The communities studied range from those inside the classroom to those off campus in which students express significant participation. This research study is in its fourth (of five) years and is a multi-university, mixed methods project. The five collaborating institutions range from small private colleges to large research institutions. Their Carnegie Classifications and their key characteristics as drawn from institutional data and mission statements are as follows:

- HBCU (Bac-Div): An historically black, independent, and state-related institution of 3000 students in the Southeast which offers seven undergraduate engineering degrees and is typically characterized by small groups of students (class sizes of 5-50). Students can begin the engineering curriculum as early as first semester freshman year.

- Private/Faith Based (Masters L): A small teaching institution in the Pacific Northwest of 4,000 students, whose mission emphasizes building graduates of competence and character by providing tools of rigorous learning and modeling a grace-filled community. This institution offers four engineering and computer science majors that are based on and informed by a Christian world view. Class sizes typically range from 15-20.

- Research (RU/VH): A large research institution and flagship university in the Pacific Northwest serves over 92,000 students and offers over 12,000 degrees annually. This institution offers ten engineering and computer science undergraduate degrees, and is characterized by large classes in freshman and sophomore years (100-500) and smaller classes in junior (40-80 students) and senior year (15-40 students). Classes are commonly supported by multiple teaching assistants and contact with faculty is less frequent than at the other four schools in this study.

- Teaching (Masters L): A medium-sized institution of over 10,000 students in the Midwest that combines an emphasis on teaching with emerging innovations in research, serving a regional student population. This institution offers over ten undergraduate degrees in engineering and computer science. Class sizes typically average 25 students, with upper division classes averaging about 15 students.

- Women's (Masters L): A small women's college of approximately 1,900 students in the Northeast with fifty majors, including three computer science and related degrees. This institution offers a liberal arts education for its undergraduates integrated with professional work experience. Class sizes are typically 6-12 students, with the largest class size around 20.

The five institutions were deliberately chosen in order to capture undergraduate experiences in a wide range of institution types that vary significantly by size (enrollments), variety of established 
engineering and computer science majors, institutional culture, and diversity of undergraduates on campus.

The research plan involves 3 phases to address the following research questions:

1) What connections to community are contributing to significant differences in academic engagement?

2) How are significant connections to community strengthened by qualities of institutions under study?

3) How are these connections to community converted to improvements in engagement in the classroom?

4) Why are institutional characteristics of the "How" phase important contributors to engagement?

Phase 0 was a tool development process that used pilot surveys, pilot focus groups and pilot interviews with faculty to gather information addressing the research question and to look at affective facts that influence student engagement and thus cognitive outcomes. The underlying model guiding decisions about what questions should be asked in surveys, focus groups and interviews is shown in Figure 1. Although the figure has many aspects, the key concepts are that 1) there are multiple ways to measure student experience, 2) these can impact connections to community (also measured in multiple ways), 3) this mediates student engagement, 4) which can lead to positive outcomes (measured in multiple ways).

Survey questions were derived from multiple surveys that have been validated in other research projects such as the Motivated Strategies for Learning Questionaire, ${ }^{25-26}$ and the Collegiate Psychological Sense of Community scale ${ }^{6}$. Qualitative approaches used the structure shown in Figure 2 to address questions of how and why.

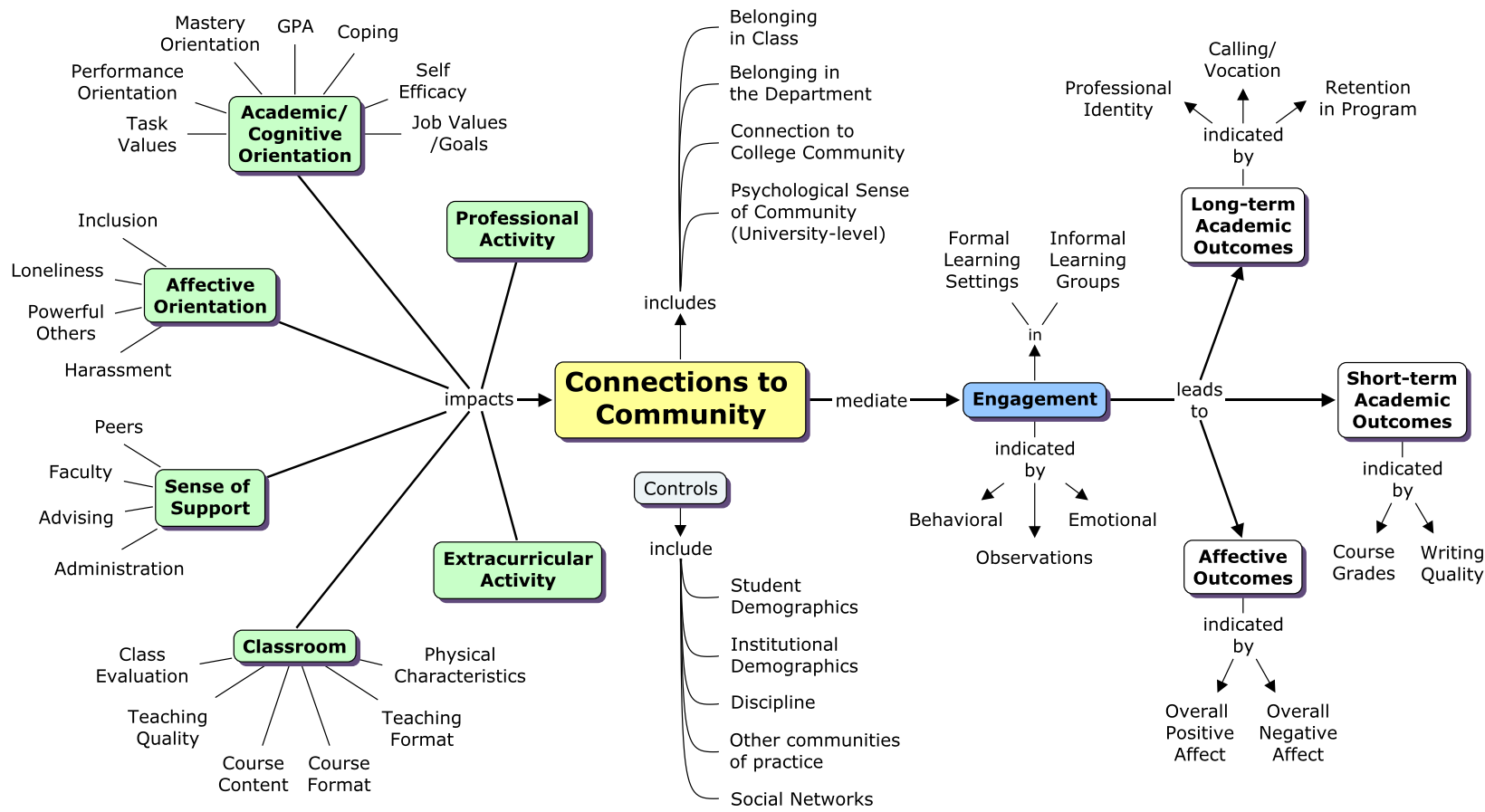

Figure 1. Conceptual model of how connections to community play a role in student learning. 
The data for the current research were derived from survey responses and focus groups. Paper surveys were administered in the middle of fall term for sophomores and in the middle of spring term for juniors. Informed consent was obtained and various incentives were offered in order to encourage participation, including small gift cards and free food. Students who completed the survey were invited to participate in focus groups (or individual interviews when more feasible) to gather more detailed information about their experience with communities. A total of 944 students from the five institutions participated in the survey data collection and 169 in the focus groups.

Instruments: A range of instruments were used to understand student connections to community including (a) Likert scale survey items that evaluated validated constructs of belonging and connection to community; (b) open-ended survey questions intended to further explore how students experienced and valued community; (c) focus group and interview questions for students that explored more deeply the role of community in their lives; and (d) corresponding questions for faculty and academic advisors that explored similar perceptions of community among students.

Table 1. Four measures of belonging in higher education.

\begin{tabular}{|l|l|l|}
\hline Construct & Context & Items \\
\hline Belonging & To Class & $\begin{array}{l}\text { I feel accepted in this class. } \\
\text { I feel comfortable in this class. } \\
\text { I feel supported in this class. } \\
\text { I feel that I am a part of this class. }\end{array}$ \\
\hline & To Major & $\begin{array}{l}\text { I feel accepted in my major. } \\
\text { I feel comfortable in my major. } \\
\text { I feel supported in my major. } \\
\text { I feel that I am a part of my major. }\end{array}$ \\
\hline & $\begin{array}{l}\text { To University as } \\
\text { Institution }\end{array}$ & $\begin{array}{l}\text { I feel like I really belong at this school. } \\
\text { I wish I had gone to another school instead of this one. } \\
\text { I wish I were at a different school. }\end{array}$ \\
& $\begin{array}{l}\text { To University as } \\
\text { Community }\end{array}$ & $\begin{array}{l}\text { People at this school are friendly to me. } \\
\text { I feel that there is a real sense of community at this school. } \\
\text { I feel like there is a strong feeling of togetherness on campus. }\end{array}$ \\
\hline
\end{tabular}

\section{Likert-Scale Survey Items:}

Belonging has been measured in a number of different contexts and communities. In the academic environment, belonging has been most often measured in the context of the classroom and whole school settings where individuals experience significant interpersonal connections. In the K-16 literature, labels for belonging have included belonging to classroom, belonging to school, ${ }^{27-28}$ group belonging, ${ }^{29}$ school membership, ${ }^{2}$ and psychological sense of community. ${ }^{30}$

Our survey items are subsets of items from the Anderson-Butcher \& Conroy measures for belonging ${ }^{29}$ and the Lounsbury \& DeNeui ${ }^{30}$ measures for psychological sense of community. Because all of our items measure aspects of regular social contact and stability consistent with the definition of belonging presented above, we consider that all of our four subscales represent 
the construct of belonging in different settings. These four settings are the classroom, the major, the university as an institution, and the university as a community. Items for each of these four measures of belonging in higher education are detailed in Table 1.

\section{Open-ended survey Questions:}

In addition to traditional Likert-scale questions, open-ended questions used in combination with Likert-scale items are helpful to further understand how students interpret these Likert-scale items and also to explore perceptions, ideas, and thoughts that students may have which fall outside the scope of the more narrow Likert-scale items. Examples of such open-ended survey items that specifically target how students are experiencing community and which communities matter most to them are as follows:

- Which communities in your life (such as family, religious organization, class, extracurricular organization) do you feel most connected to?

- Which communities in your life (such as family, religious organization, class, extracurricular organization) do you feel least connected to?

- On average, how many hours do you spend per week in extra-curricular activities (religious organization, book club, fraternity, professional societies, etc.)?

Although these items cannot be fully analyzed with traditional statistical analysis techniques, they offer deeper insight into the student experience than more quantitative, closed-ended items.

\section{Student focus group and interview questions:}

Study 1 is a multi-phase study intended to understand deeply how students experience community in different cultures and how it influences their academic experience. In the first phase of the research (Phase 0), focus groups were assembled among students to explore the broad space of community and influences on that community. Different themes emerged from this phase of the research by institution and these themes were specifically explored in more detail during the second phase (Phase 1) of the research. Examples of interview and focus group questions used during Phase 1 based on what students most emphasized in Phase 0 are provided below:

- How does the size of the <institution or community name> (including the wide variety of majors, the large number of students, large class sizes etc.) help or hinder your ability to engage in your education or your ability to be a part of community here?

[Probing/Follow-up Questions:] Can you tell me more about how that influences the way you engage in your classes? How that influences the way you participate in community? Can you tell me more about what that looks like?

- Is there anything else about the <institution or community name> that specifically influences how well you engage in your education or how fully you can be a part of community here?

[Probing/Follow-up Questions:] Can you tell me more about how that <specify a particular characteristics of the university> influences the way you engage? The way you participate in community? Can you tell me more about what that looks like? Is that a good thing or a bad thing? 
- Of all the academic communities you participate in (laboratory groups, informal study groups, the classroom, activities sponsored by the department and so on), which help you the most to engage in your education? How do they help you?

- Of all the non-academic communities you participate in (athletics, church groups, work communities, international student groups, fraternities \& sororities, church groups, and so on), which help you the most to engage in your education? How do they help you?

[Probing/Follow-up Questions:] Is there anything else that particularly influences how well you participate in class, lab, or informal study groups? What makes the most difference? How does it make a difference?

These items emphasize understanding how institutional factors and other aspects of the student experience influence their community engagement (in this case, the classroom and other learning environments) and ultimately, their academic experience. Questions can be readily modified and the research design adjusted to explore similar research questions in any service learning, outreach, international, or other off-campus experience.

\section{Faculty and Advisor Interview Questions:}

In order to both understand and offset bias introduced by the student perspective of particular communities and experiences, a separate interview protocol designed to explore the perspectives of leaders in that community is also helpful. In Study 1, the leadership groups interviewed included both faculty and advisors to undergraduate students. Examples of questions asked of these groups with the intent of understanding the community experience follow:

- What are the characteristics of good community? What do you think are the differences between being in a group and being in a community?

- When you think of good community for a student (one that enables the student to belong and to feel fulfilled), what words <or adjectives> come to mind that describe that community?

- Which communities do you perceive that your students enjoy the most (such as the classroom, laboratory, informal study groups, student professional society meetings, church, athletic teams)?

- Which communities at the <community or institution> do you perceive make the $<$ institution> a special place for students to truly belong?

- Which communities do you wish the <community or institution> had that would help to make this institution a special place where students can truly belong?

- What is it about the <community or institution> that makes it a good community? a bad community?

- Can you tell me anything more about how community (both inside and outside the classroom) plays a role in the student experience here at the <community or institution>?

Result Highlights: Although connections to community were studied in both academic and nonacademic communities in this study, the highlights presented here are those that are most directly relevant to our target audience: those practitioners, leaders, and researchers invested in service 
learning and other outreach communities for engineers. We emphasize in our research highlights the role that participation in out-of-class communities has in influencing student academic constructs or outcomes (Figure 2). Although data analysis for our longitudinal data is not yet complete, the cross-sectional results presented here do suggest likely directions for our longitudinal outcomes.

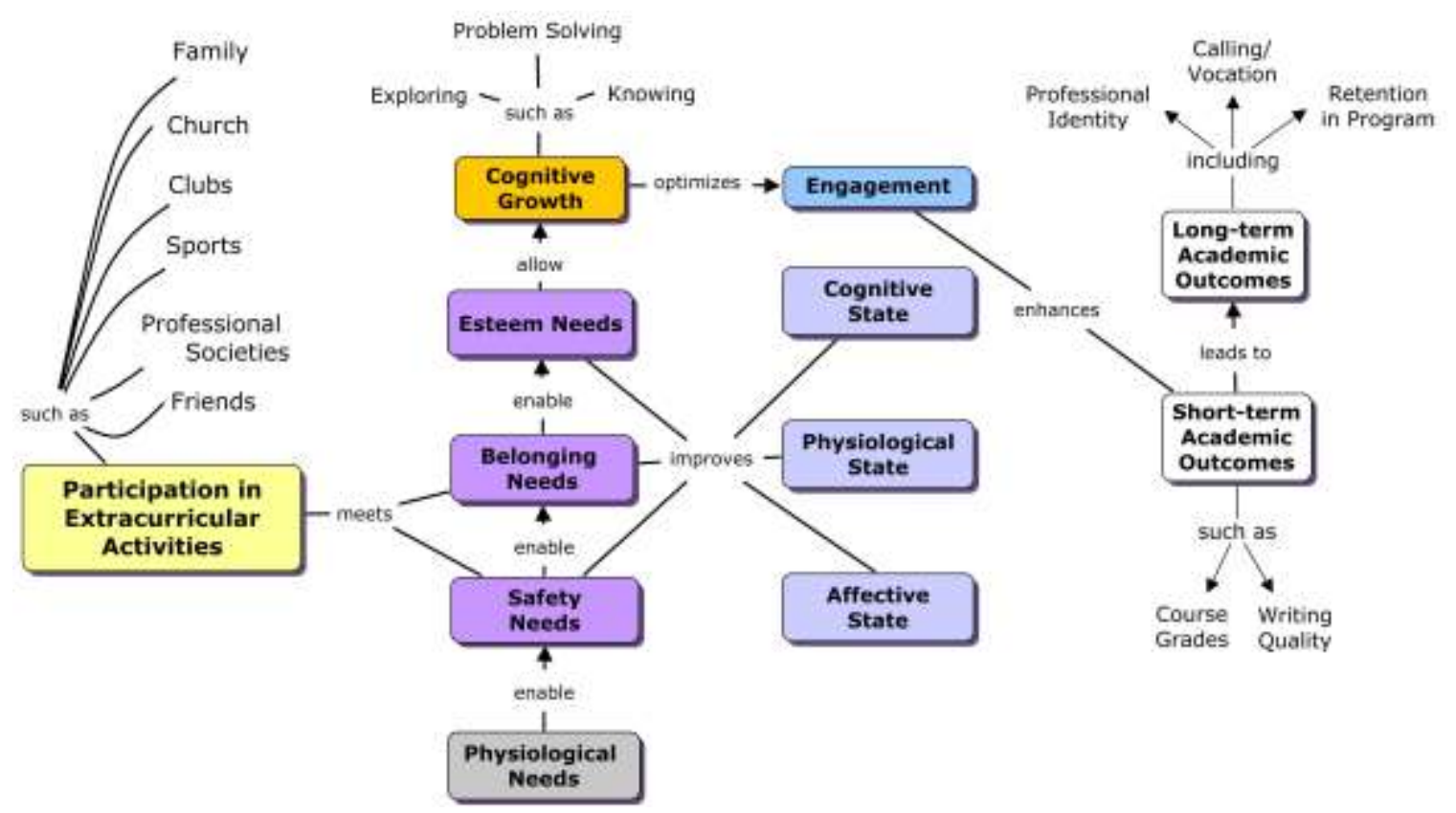

Figure 2. Approach to understanding how students experience extracurricular activities.

Aggregate responses to the survey question: "Which communities in your life (such as family, religious organizations, class, extracurricular organizations) do you feel most connected to?" over four of the five institutions involved in this study have been analyzed. By a wide margin over all other outside communities, students reported that they felt most connected to their families. At all institutions, over $60 \%$ of students felt most connected to their families. Following family, between $9 \%$ and $28 \%$ of students reported that friends, and religious organizations (listed as 'church'), clubs (primarily on-campus), and classes were the communities to which they developed the strongest connections during their undergraduate years. Very few students (less than $2 \%$ ) reported strong connections to the university/college as a whole, to community service organizations, music (bands, choir, etc.), or to trade organizations within engineering (including research groups and design project competition teams).

Clearly, engineering students pursue and experience many benefits from participating in outside communities during their undergraduate years. Some students choose to focus entirely on their studies, which can be understandable due to the rigor and heavy workloads characteristic of engineering majors. When students do indicate strong connections to outside communities, however, they are surprisingly aware and strategic in how these connections relate to their academic pursuits. Most often, students seem to meet belonging needs through connections to outside community, although they also seek these communities to relieve anxiety (safety needs), establish order in an otherwise chaotic life (safety needs) and build their self-confidence (esteem 
needs).

When looking specifically at the extent to which extracurricular involvement can correlate to academic outcomes, our results show that links between extracurricular involvement and academic engagement only emerge for those students who are involved in extracurricular activities past a certain threshold. Students involved at greater than average levels tend to feel less stressed, less anxious, and less frustrated in the classroom. Our results are not yet longitudinal, so we cannot say for certain that extracurricular involvement is reducing stress in the academic environment for students. However, we do know that highly engaged students (in the classroom) do not tend to be more engaged overall, which suggests that a causal link between extracurricular involvement and engagement is likely and well worth assessing within a related longitudinal study.

Thus, in future studies of community, both on and off campus, it will be important not only to study why these students are more vulnerable to these negative levels of engagement, but also whether or not extracurricular activities (and which specific types) can help students in these atrisk groups offset whatever is augmenting their stress, anxiety, and frustration.

These highlights are taken both from both published and in-review analyzes of our data. Further supporting information can be found in previously published works. ${ }^{31-35}$

Study 2: Engineering students' development and usage of social capital can be influential on their decisions to select engineering as a college major and persist at the undergraduate level. The communities (e.g., family, school personnel, friends) to which students have access and the degree to which they are integrated into these communities can have differential impact on the resources available to them related to pursuing engineering. The ways in which students develop social capital and the degree to which they activate resources during their undergraduate experience are also influenced by their strength of ties with related communities. This research study is a multi-institution, mixed-methods project. The goal of this project is to develop a conceptual model for how students develop, access and activate social capital in making decisions about their engineering academic and career plans.

\section{Instruments and approaches used:}

Table 2. Purpose and Advantages of the Mixed-Methods Research Design in Study 2.

\begin{tabular}{|c|c|}
\hline Quantitative: Name \& Resource Generator & Qualitative: Critical Decision Node Interviews \\
\hline $\begin{array}{l}\text { Purpose: } \\
\text { - Quantitatively measure engineering related social } \\
\text { capital (accessed and activated) of individual } \\
\text { students } \\
\text { - Determine the resource providers for students' social } \\
\text { networks }\end{array}$ & $\begin{array}{l}\text { Purpose: } \\
\text { - Understand specific mechanisms of social capital- the } \\
\text { "how and why" of access and activation } \\
\text { - Clarify results from quantitative phase } \\
\text { - Gain in-depth picture of individual's academic and } \\
\text { career choice process through thick, rich description }\end{array}$ \\
\hline $\begin{array}{l}\text { Advantages: } \\
\text { - Allows identification of group level patterns using a } \\
\text { comparatively large dataset } \\
\text { - Relatively quick data collection }\end{array}$ & $\begin{array}{l}\text { Advantages: } \\
\text { - Participants describe experiences in their own words } \\
\text { - Potential to answer questions raised by quantitative } \\
\text { results }\end{array}$ \\
\hline
\end{tabular}


The instruments developed for this project were created based on sociological "name generator" and "resource generator" survey instruments for measuring social capital, and were adapted and designed specifically for the context of engineering education to elicit responses about the role of social capital in students' decisions to enter and persist in engineering at the undergraduate level. Participants were asked to answer survey items thinking of two different time points: retrospectively when they were making the decision to choose engineering as a college major, and at the current time during their undergraduate studies. In this way, the survey was designed to account for changes in social capital over time while requiring administration only one time. The "name generator" portion of the survey asks respondents to produce up to eight names of people who they consider to be influential in their academic and career making decisions, and then answer a series of questions about their relationship with each person as well as the person's demographic information. Respondents were first asked to respond while thinking of the time during which they were making their decision to enter engineering (Time Point 1) and then at the current time (Time Point 2). This approach is a person-centered approach, which provides details about who is in participant's social network. It tends to bias toward stronger ties, because these are the names that more immediately come to the participant's mind.

The "resource generator" portion of the survey presents a series of resources related to engineering academic and career decisions at each time point. This resource focused technique, elicits weaker ties, as the resources are not necessarily provided by the list of people the participant named in the "name generator" portion. If the participant indicated that they had access to a resource (e.g. "writes you a reference letter," "helps you find internships, jobs or scholarships," "introduced you to people in their professional network"), then they are asked to select from a list indicating who provided the resource. Examples of people providing resources include "college/university professor," "employer or coworker, "college/university personnel such as academic advisors or program directors." More details about the instrument and its administration can be found in Martin et al. ${ }^{36}$

1,401 participants at five universities responded to the survey. The researchers employed purposive sampling (from among the survey participants) and conducted 56 individual interviews employing the critical incident technique.

Result highlights: Cluster analysis is a powerful data analysis technique that the researchers have used examine survey data beyond typical demographic dimensions (e.g., race/ethnicity, sex, year in school), and rather groups student participants into similar categories ("clusters") based on their social capital characteristics. Additional data analysis for this project is ongoing.

Four cluster analyses were performed: two for the Name Generator (NG) data (one at the first time point and one at the second), and two for the Resource Generator (RG) data (again, one for each time point). The four cluster analyses each yielded a two-cluster solution (in each case, Cluster 1 contains students whose social capital characteristics are "higher", and Cluster 2 contains students whose social capital characteristics are "lower"), resulting in a total of 8 clusters at each time point. Thus, each participant is assigned to one of two clusters at each time point based on (a) their responses to the Name Generator and (b) their responses to the Resource Generator. 
The cluster analysis grouped participants into various clusters, but since multiple analyses were conducted at each time point (one NG cluster assignment and one RG cluster assignment per participant per time point), unique identifiers for students' social network characteristics were created by pairing their clusters into "quadrants" (one quadrant assignment per participant per time point), and tracking the shift in quadrants over time with the "quadrant shift" (one cluster shift group assignment per participant).

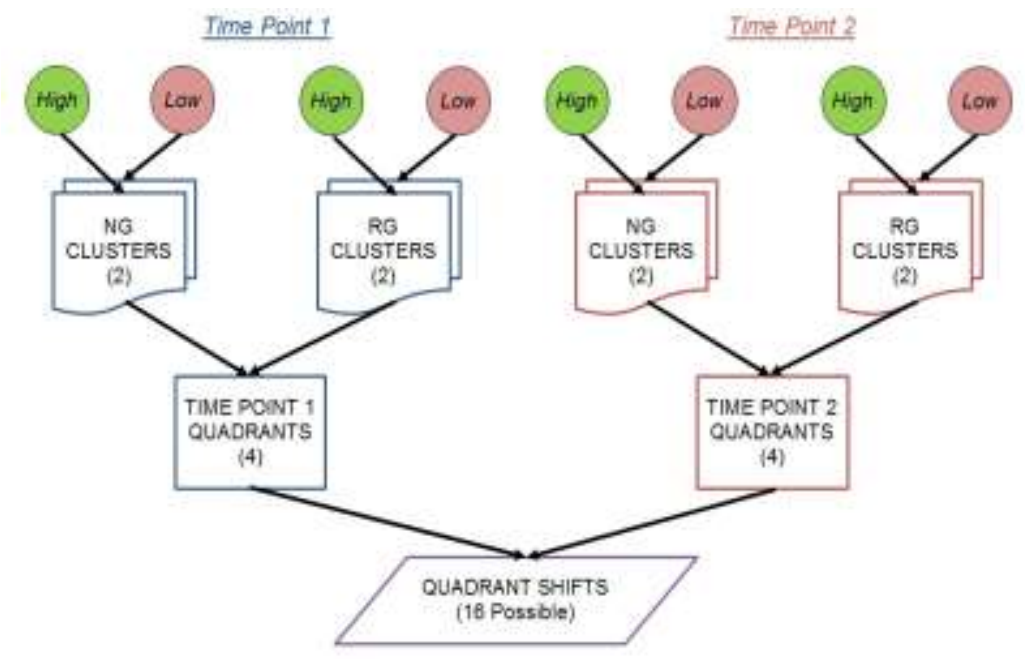

Figure 3. Cluster analysis.

By pairing the $\mathrm{NG}$ and $\mathrm{RG}$ cluster assignments for each student at the first time point, it was possible to determine which students had consistently higher levels of social capital resources (theoretically "richer" networks; high NG and high RG) which students had lower levels of social capital resources (theoretically "poorer" networks; low NG and low RG), and which were in between (either high NG, low RG or low NG, high RG). This information is visually represented by plotting the NG clusters on the abscissa and the RG clusters on the ordinate to show that each student can be assigned to one of four quadrants based on their (NG, RG) social capital network characteristics (Figure 4). Participants who were categorized into Quadrant 1 (N $=211$ ) exhibited "lower" social capital indicators in both the Name Generator and Resource Generator, participants in Quadrant $2(\mathrm{~N}=450)$ exhibited "higher" social capital characteristics in the Name Generator, but "lower" social capital characteristics in the Resource Generator, and so forth. By performing the same analyses to the data obtained at the second time point of the survey, we can observe how students' social capital shifts during the time they have spent in college engineering studies.

In order to identify and describe how participants' developed and activated social capital, the researchers are investigating "quadrant shifts" over time that occur for the various clusters, that is, the different ways in which the participants change in their NG clusters, RG clusters, or both, over time (from the time when they were considering engineering as a college major to the time of the survey participation as an undergraduate engineering student). As an example, quadrant shifts representing various types of increases in social capital characteristics are shown by the arrows in Figure 5. 


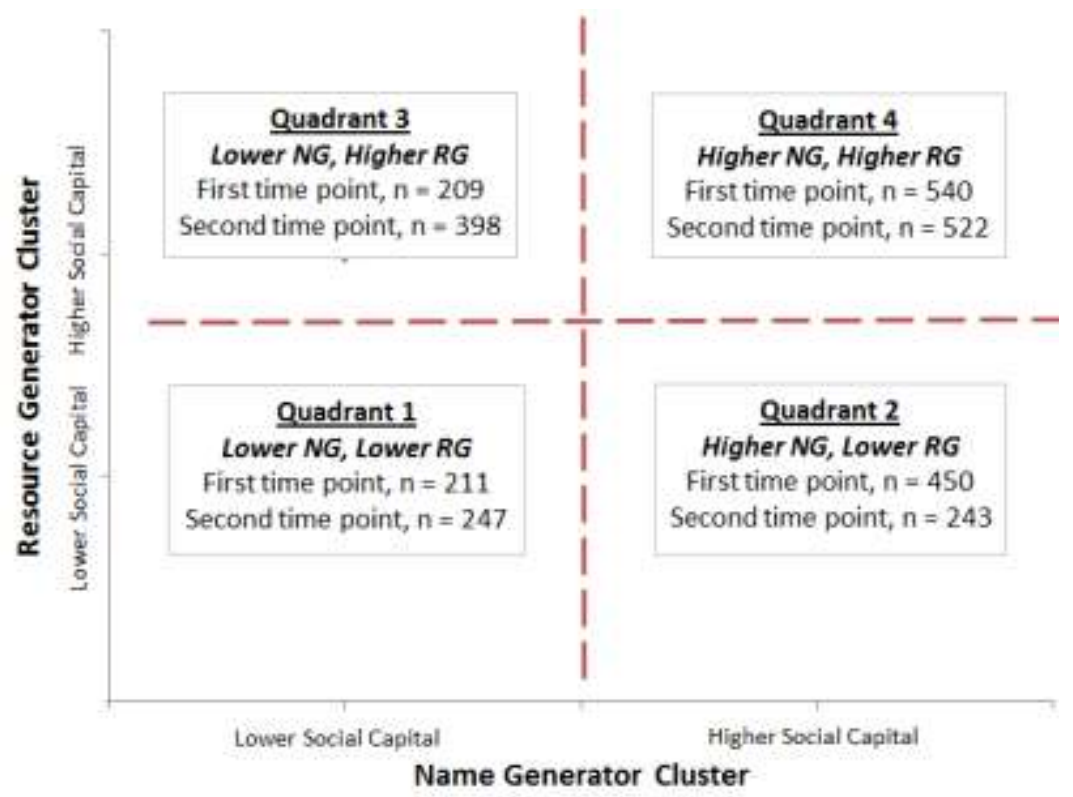

Figure 4. Clusters.

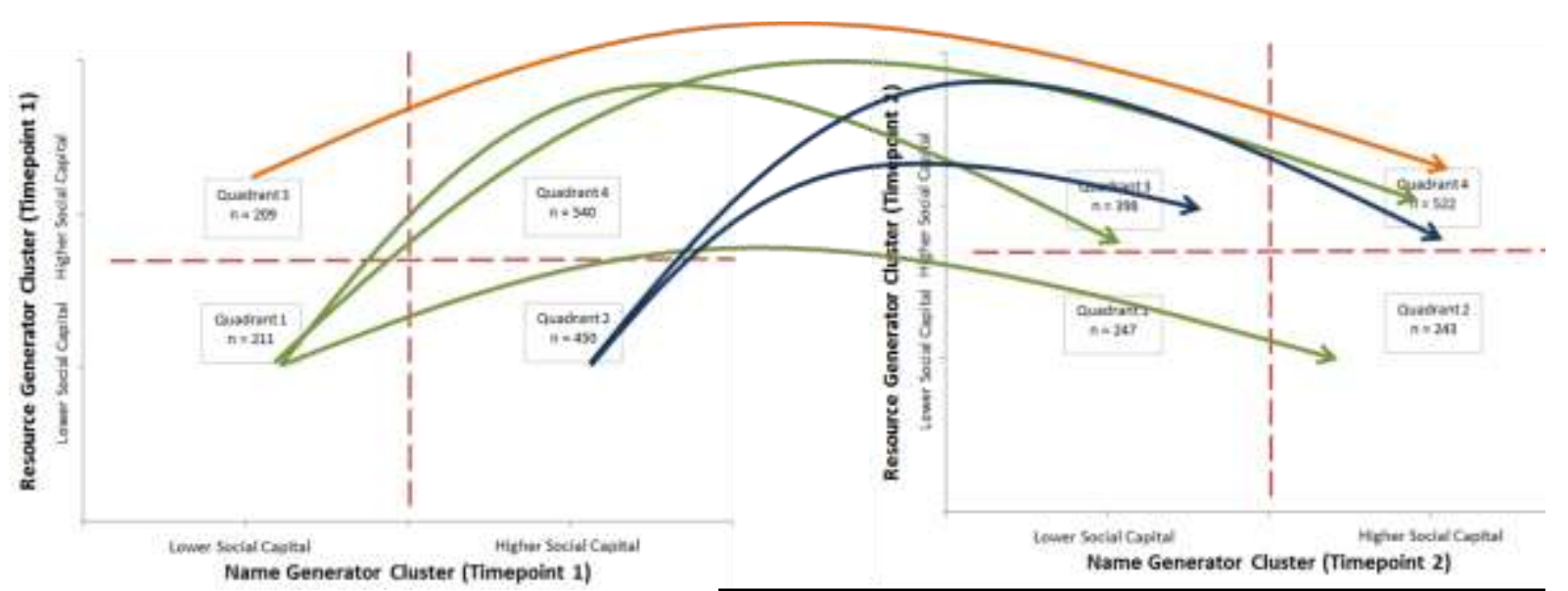

Figure 5. Social capital shifts over time.

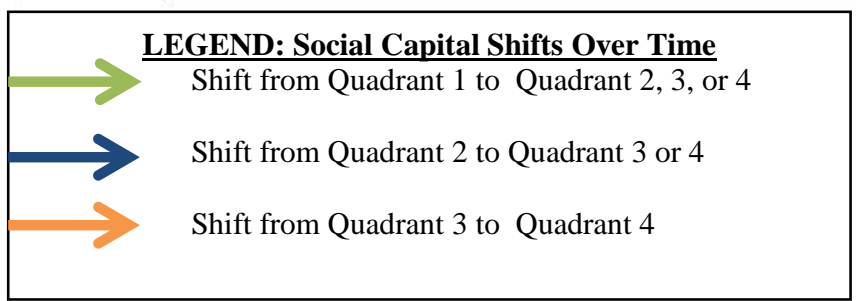

Since there are four quadrants at the first time point and four at the second time point, there are a total of 16 possible cluster shift "routes" between the time points. For example, a quadrant shift of " $1 \rightarrow 1$ " means the participant was assigned to Quadrant 1 at the first time point, and remained in Quadrant 1 at the second time point - maintaining a relatively low level of social capital resources. Such a shift (or lack thereof) would indicate that the student has not gained access to many additional social capital agents or engineering-related resources during their time as an engineering undergraduate. On the other hand, a quadrant shift of " $2 \rightarrow 4$ " means a participant 
shifted from Quadrant 2 to Quadrant 4 during their time at college - maintaining a higher level of NG social capital, but increasing their RG social capital to a higher level and/or quality than before becoming an undergraduate engineering student. Such a shift would indicate that there may have been positive experiences/relationships created during their time as an engineering student resulting in the student having greater access to engineering-related resources.

Knowing how a student's social capital structures change over time is a valuable finding, but it does raise many additional questions that need to be addressed. Current efforts are focused on determining potential differences among the quadrant shift groups which would indicate that certain student participants (groups based on differences including race/ethnicity, length in school, generational status) are more likely than others to experience a certain type of shift in social capital. In other words, can we seek to identify "personas" within the clusters/quadrants/shifts that describe traits of a typical student experiencing that shift. Current analyses include characterizing social capital "personas" based on these group level data. Additional analyses are being conducted in order to identify which social capital variables are significant for various groups. While the goal of this study is to use analyses of qualitative data to understand the quantitative trends and fully develop the conceptual model, the interaction between quadrant shift groups and engagement with off-campus communities is a potential avenue for exploration.

\section{Challenges}

There are many challenges to doing any research that involves human subjects. Interacting with Institutional Review Boards can be a struggle but is an important part of protecting subjects. Much educational research, particularly of university students over the age of 18 , has the potential to be declared exempt. However, review boards typically need full applications in order to assess this. Seeking out local mentors in fields that often work with human subjects, such as education, psychology and sociology can make this process smoother. One benefit of the process is that external review of your work plan and collection instruments can result in more clear instructions and processes for your subjects.

Once a process is approved, data collection has its own challenges. When doing quantitative research, sample sizes are an issue. Recruiting sufficient participants, whether for surveys, focus groups or interviews, can be a hurdle. Tactics include incentives such as gift cards, free food, extra credit in classes, and personal appeals. Especially when attempting to oversample in order to gather data from underrepresented students, a personal request can make a difference. Sometimes, email appeals from faculty work and sometimes email appeals from graduate researchers work. Researchers should be aware of the power relationships they may be in with students and construct methods to avoid knowing about participation when it could potentially affect grades (or the perception of how grades are awarded).

Single institution projects may have issues with sample sizes or control groups. One way to address this and support generalizability of results is to partner with another institution. While this increases sample sizes, there are additional challenges related to reliability. When multiple interviewers and observers take part in data collection, care must be taken to insure that training is consistent and that observation ranges are calibrated. For longitudinal collection, this can also 
affect single institution projects as student research assistants turn over. Planning regular communication to calibrate data collection processes will support reliability.

Working with multiple institutions also has a number of challenges. It is recommended that when seeking institutional commitment for a project (for example, during the proposal writing process), that the researcher enlists a specific site coordinator/champion. Offering a stipend to this person can help increase buy-in, but even so, it is well-advised to keep in mind that they are rarely going to give the project the same priority level as the PI, which is can cause time delays and can requires extra attention. Another option is to develop full research collaborations with coPIs at other institutions. Both approaches are represented here.

Additionally, while working with multiple institutions can help achieve theoretically saturated samples for qualitative research, a single PI traveling to various locations for in-person interviews and observations is expensive and time consuming. However, this cost may be worth it as one author's experience with doing in-person vs. phone interviews supports the notion that face-to-face interviews are necessary to establish rapport with interview participants.

Developing reliable data collection processes with multiple local interviewers can address this problem, but is difficult for a single PI project.

The advantages for using a mixed-methods research plan are extensive, because of the breadth and depth of learning that can be gained. However, using both quantitative and qualitative methods requires expertise in many areas and can be a challenge on its own. One way to address this is to have experts with a variety of experience associated with project. On one's own campus, experts in statistics for qualitative work or interviewing and data coding for quantitative work can be a treasure for supporting work in engineering education research.

\section{Resources}

Instruments from Study 1 are available through http://www.ee.washington.edu/research/community/Community/Home.html.

Instruments and models from Study 2 can be requested through Dr. Julie Martin (jtrenor@clemson.edu).

\section{Summary}

In Study 1, the role of community as it is associated with student engagement in academic endeavors can range from negative to negligible to positive, depending on the community, the amount of involvement, and the student's role in that community. These types of research results are far more mixed that in K-12 environments where extracurricular activities are largely associated with student gains in learning and engagement in the academic arena. Because of these mixed results and the wide range of how students experience community, it is important to study each community in the context of the overall academic experience individually, so that a rich understanding of that community's role in the overall student experience is established and does not get lost in the heterogeneous nature of communities in higher education. 
For example, Study 1 has found that extracurricular activities are often associated with positive academic benefits via numerous avenues, many of which service-learning and cooperative learning could also provide. For instance, interviews with students revealed that while friendships naturally meet belonging needs, and to some extent esteem needs, "friends also seem to play a critical role in fulfilling safety and security needs, as students often referred to the role of spending time with friends in diminishing anxiety and enhancing stability...Students often made explicit connections between meeting these needs and their resulting academic engagement." 31 Student surveys conducted as part of Study 1 indicate that "women tend to more frequently $(22.2 \%)$ cite peers as important friendships in their lives compared to men (10.1\%)"35. Thus, while friendships seem to play an almost universally positive and broad-based role in meeting student needs and enhancing the student experience, differences between genders and other demographic groups are important to understanding how to relate to these groups and further support a positive community-based experience. While friendships play a localized daily role in supporting students within communities, other communities such as those provided by religious activities can enable a more transcending experience. Church activities can enable academic engagement via such a transcendent experience: "Church helps me focus. It helps me to really remember why I'm here and who I'm doing this for." Other communities, however, such as on-line social networks can play a negative role in the academic experience, thus necessitating a more detailed understanding of how communities influence students and which aspects should be enhanced and which should be diminished. Service learning, outreach, and international experiences are understandably complex, heterogeneous environments that can provide substantial benefits to students. However, these environments can be equally vulnerable to negative impacts. Comprehensive evaluation of these outreach and off-campus efforts can prevent negative impacts from impairing perception of what are overall, positive and often lifechanging communities for many students.

Learning about the ways that involvement with off-campus communities support student learning will support the implementation of non-traditional learning approaches. This paper and interactive session provide a starting point for practitioners interested in rigorous assessment of their service learning and community engagement

\section{Acknowledgements}

The authors would like to gratefully acknowledge the National Science Foundation for their support of this work under the REESE program (grant numbers DRL-0909817, 0910143, 0909659, 0909900, and 0909850) and under the CAREER program (EEC-0950710).

\section{References}

[1] National Academy of Engineering (2004). The Engineer of 2020: Visions of Engineering in the New Century, National Academy of Engineering, 2004. Available at http://www.nap.edu/openbook.php?isbn=0309091624. Accessed January 6, 2013.

[2] Goodenow, Carol (1993a). Classroom belonging among early adolescent students: Relationships to motivation and achievement. Journal of Early Adolescence, 13, 21-43

[3] Goodenow, Carol (1993b). The psychological sense of school membership among adolescents: Scale development and educational correlates. Psychology in the Schools, 30, 79-90. 
[4] Ryan, A. M., \& Patrick, H. (2001). The classroom social environment and changes in adolescents' motivation and engagement during middle school. American Educational Research Journal, 38(2), 437-460.

[5] Center for Educational Statistics (September 1993). Dropout Rates in the United States- 1992, U.S. Department of Education, Office of Educational Research and Improvement.

[6] Brainard, Suzanne G. \& Carlin, Linda (October 1998). A Six-Year Longitudinal Study of Undergraduate Women in Engineering and Science. Journal of Engineering Education, 87(4), 369-375.

[7] Kraemer, Barbara A. (1997). The Academic and Social Integration of Hispanic Students into College, Review of Higher Education 20(2), 163-179.

[8] Tinto, Vincent. (1975). Dropout from higher education: A theoretical synthesis of recent research. Review of Educational Research, 45, 89-125.

[9] Tinto, Vincent. (1987). Leaving college: Rethinking the causes and cures of student attrition. Chicago: University of Chicago Press.

[10] Tinto, Vincent. (1993). Leaving college: Rethinking the causes and cures of student attrition, Second Edition. Chicago: University of Chicago Press.

[11] DeNeui, Daniel L.C. (2003). An Investigation of First-Year College Students' Psychological Sense of Community on Campus. College Student Journal, 37, 224-234, June.

[12] Libler, Joan \& McConnell, Charles (2004). Management Principles for Health Care Professionals, 5th ed., Jones \& Bartlett Publishes, Inc.

[13] National Center for Education Statistics (2000). Research and Development Report August 2000, Entry and Persistence of Women and Minorities in College Science and Engineering Education, Samuel S. Peng, Project Officer, U. S. Department of Education, Office of Educational Research and Improvement NCES 2000-601.

[14] Treisman, U. (1990). Teaching mathematics to a changing population.Report of the Professional Development Program at the University of California, Berkeley, 68588-0111.

[15] Treisman, U. (1992). Studying students studying calculus. College Mathematics Journal, 23.

[16] Lee, Linda \& Wilson, Denise (2005). Empowering the Engineering Undergraduate in an Era of Economic Globalization, Frontiers in Education Conference: Indianapolis, Indiana.

[17]Lee, Linda \& Wilson, Denise (2006). The Impact of Affective and Relational Factors on Classroom Experience and Career Outlook among First-year Engineering Undergraduates, Frontiers in Education: San Diego, California.

[18] Baumeister, Roy F. \& Leary, Mark R. (1995). The Need to Belong: Desire for Interpersonal Attachments as a Fundamental Human Motivation. Psychological Bulletin, 117(3), 497-529.

[19] Felder, Richard, and Brent, Rebecca (2005). Understanding Student Differences. Journal of Engineering Education, 94, 1, 57-72.

[20] Corbin, J., \& Strauss, A. (2008). Basics of qualitative research: Techniques and procedures for developing grounded theory. Thousand Oaks, CA: Sage Publications.

[21] Strauss, A. \& Corbin, J. (1990). Basics of qualitative research: Grounded theory procedures and techniques. Newbury Park, CA: Sage.

[22] Chism, N., Douglas, E. and Hilson, W. (2010). "Qualitative Research Basics: A Guide for Engineering Educators," https://cleerhub.org/resources/8.

[23] Creswell, J. W. (2003). Research design: Qualitative, quantitative and mixed methods approaches, 2nd ed. Thousand Oaks, CA: Sage Publications.

[24] Johnson, R. B., \& Onwuegbuzie, A. J. (2004). Mixed methods research: A research paradigm whose time has come. Educational Researcher, 33(7), 14-26.

[25] Pintrich, P.R. and DeGroot, E. V. (1990). Motivational and self-regulated learning components of classroom academic performance, Journal of Educational Psychology 82(1), 33-40.

[26] Pintrich, P.R., and Schunk, D. (1996). Motivation in education: Theory, research and application, Ch.3, Englewood Cliffs, NJ, Prentice-Hall.

[27] Anderman, L. H. (1999). Classroom goal orientation, school belonging and social goals as predictors of students' positive and negative affect following the transition to middle school. Journal of Research and Development in Education, 32, 89-103.

[28] Pittman, L.D., \& Richmond, A. (2007). Academic and psychological functioning in late adolescence: The importance of school belonging. Journal of Experimental Education, 75, 270-290.

[29] Anderson-Butcher, D., \& Conroy, D.E. (2002). Factorial and criterion validity of scores of a measure of belonging in youth development programs. Educational and Psychological Measurement, 62, 857-876.

[30] Lounsbury, J.W. and De Neui, D. (1996). Collegiate psychological sense of community in relation to size of college/university and extroversion, Journal of Community Pyschology, 24 (4), 381-394. 
[31] Allendoerfer, C., Wilson, D., Bates, R., Crawford, J., Jones, D., Floyd, T. Veilleux, N., (2012). "Strategic pathways for success: From social \& extracurricular activity to academic engagement," Journal of Engineering Education, July.

[32] Floyd Smith, T., Wilson, D., Jones, D., Plett, M. Bates, R., Veilleux, N. (2012). "Investigation of Belonging for Engineering and Science Undergraduates by Year in School," Proc. 2012 American Society for Engineering Education Annual Conference \& Exposition, June.

[33] Plett, M., Floyd-Smith, T., Wilson, D., Jones, Veilleux, N., Bates, R. (2011). "STEM Seniors: Strong Connections to Community Are Associated with Identity and Positive Affect in the Classroom," Proc. 2011 American Society for Engineering Education Annual Conference \& Exposition, June.

[34] Veilleux, N., Bates, R., Jones, D., Crawford, J., Allendoerfer, C., Floyd-Smith, T. (2013). "The Relationship between Belonging and Ability in Computer Science," SIGCSE (Computer Science Education) 2013, March 69, 2013.

[35] D. Wilson, D. Peter, R. Bates, J. Crawford, D. Jones, T. Floyd-Smith, N. Veilleux, (2012). "Communities that Make a Difference: The STEM Student Perspective," Frontiers in Education, Seattle, WA, October 2012.

[36] Martin, J.P., Gipson, K. and Miller, M.K. (2011). "Developing a Survey Instrument to Characterize Social Capital Resources Impacting Undergraduates' Decisions to Enter and Persist in Engineering." Proceedings of the 2011 Frontiers in Education Conference, Rapid City, South Dakota. 